\title{
Effect Of Kolawole's Problem-Solving Teaching Strategy On The Academic Performance Of Secondary School Students In Mathematics In Nigeria
}

\author{
Olofin S. O. (Ph.D) \\ Dept. of Science Education, Faculty of Education, \\ Ekiti State University, Ado - Ekiti. \\ E. B. Kolawole (Ph.D) \\ Institute of Education, Faculty of Education, \\ Ekiti State University, Ado - Ekiti.
}

\begin{abstract}
The study examined the effects of Kolawole's Problem Solving (KPS) teaching strategy on the academic performance of secondary school students in Mathematics in Nigeria. Specifically, the study was designed to ascertain which of the strategies (KPS or conventional) would be the more effective in the teaching of Mathematics. The study also investigated the difference in the academic performance of students exposed to KPS strategy in three geo-political zones of Nigeria. Quasi - experimental pre-test and post-test two group design (one experimental group and one control group) was used in the study. The sample consisted of 562 S.S.S. 2 students drawn from eighteen public secondary schools in three geo-political zones of Nigeria. The sample was selected using multistage sampling procedure. Performance Test in Mathematics (PTM) was used to collect relevant data for this study. The data were analyzed using descriptive and inferential statistics at $\mathbf{0 . 0 5}$ level of significance. The findings of the study showed that the two groups (KPS and Conventional) were homogeneous at the commencement of the experiment. Also, there was significant difference in the post-test mean score of students exposed to KPS and conventional strategies in favour of students exposed to KPS strategy. Furthermore, there was difference in students' performance in Mathematics when exposed to KPS based on their geo-political zones. Based on the findings of the study, it was recommended among others that the use of KPS strategy should be encouraged in Mathematics class in secondary schools so as to enhance better academic performance of students in Mathematics.
\end{abstract}

Key words: Kolawole's Problem-Solving, Academic Performance, Students, Mathematics

\section{INTRODUCTION}

Mathematics is an instrument that facilitates the learning of all subjects (Kolawole \& Popoola, 2009; Kolawole and Olofin, 2018). No wonder Plato (a philosopher and mathematician) said Mathematics is the bedrock of all other subjects and that is the reason why he said "let no man make destitute of mathematics" (Joseph, 2012). Hence, application of Mathematics cut across all areas of human knowledge. Despite these wide applicability and importance of Mathematics many students are still not finding their feet in the subject as a result of their perennial failure in the subject

It was specifically observed by the researcher that the performance of students in Mathematics in three geo-political zones under consideration as announced by West African Examination Council was below average. WAEC recorded a mass failure in Mathematics from 2014-2016 where an average of $58 \%, 52 \%$ and $66 \%$ of the candidates who sat for the examination in 
South-West, South-East and North-Central geo-political zones respectively failed Mathematics (WAEC, 2017). This unfortunate trend should agitate the minds of Mathematics educators in Nigeria.

The researcher observed that the most common method used by Mathematics teachers in secondary schools is the conventional method which is lecture method. Teachers seem to be comfortable with this method because they are in control of content and time. It appears that this method has not yielded much success and could be contributing to the poor performance of students in Mathematics. Student's perception and assimilation of the subject matter appears to be usually very slow (Kolawole \& Olofin 2018).

It has therefore become necessary to seek effort that will employ an approach or approaches that will enhance better academic performance of students in Mathematics. Several strategies like lecture method, project method, activity-based method among others have been advocated for improvement of teaching and evaluation in the classroom, yet the problem has remained largely unsolved. Consequent upon the aforementioned, the development of a proactive problem-solving method capable of being adopted for the overhauling of the system seems necessary. In response to this, Kolawole's Problem-Solving (KPS) teaching strategy, \{which had been internationally published and globally certified for usage by leading education experts across the globe\} was postulated (Kolawole, 2013).

Kolawole's Problem-Solving (KPS) teaching strategy is a five steps teaching strategy. In step 1, the teacher will adequately make effort to identify all relevant keywords, terms and terminologies (KTT) associated with the problem/topic upon which questions would be formulated. In step 2, the teacher 'DIRECT' the Problem/Topic via $\mathrm{D}, \mathrm{I}^{2}, \mathrm{R}^{3}, \mathrm{E}, \mathrm{C}^{2}, \mathrm{~T}^{2}$. In teaching and evaluating students at this ability level, the verbs that can be used include: Define, Identify, Indicate Recognise, Relate Regulate, Enumerate, Categorize, Classify and Solve all Identified Keywords (K), Terms (T), Terminologies (T) [IKTT] of the problem/topic or equivalent verbs or synonyms of the problem/topic (Kolawole \& Olofin, 2017).

In step 3 of KPS strategy, the teacher 'DEVECQUIT' the Problem/Topic via D,E,V,E, $\mathrm{C}^{3}, \mathrm{Q}^{2}, \mathrm{U}, \mathrm{I}, \mathrm{T}^{2}$. The verbs to be used for teaching and evaluating students at this level include Discuss, Explain, Verify, Expatiate, Criticize, Compose, Compare Query, Understand, Inquire, Transform all Identified Keywords (K), Terms (T), Terminologies (T) [IKTT] of the problem/topic or equivalent verbs or synonyms of the problem/topic. While in stage 4 of this strategy, the teacher 'SCRIPT' out the Problem/Topic via $\mathrm{S}^{3}, \mathrm{C}^{3}, \mathrm{R}, \mathrm{I}, \mathrm{P}, \mathrm{T}^{3}$. The verbs for teaching and evaluating students at this level include Solve, Simplify, Sketch, Calculate, Compute, Construct, Read, Interprete, Plot, Tabulate and Transform all Identified Keywords (K), Terms (T), Terminologies (T) [IKTT] of the problem/topic or equivalent verbs or synonyms of the problem/topic.

In the final stage of the strategy which is step 5, the teacher 'APPRAISE' the topic via $A, P, P, R, A, I, S, E^{2}$. The evaluative verbs for evaluating students' ability at this level include: Apply, Preview, Predict, Review, Assess, Induce, Summarize, Estimate and Examine all Identified Keywords (K), Terms (T), Terminologies (T) [IKTT] of the problem/topic or equivalent verbs or synonyms of the problem/topic. In summary, the five steps of KPS are:

i. 'IKTT' the Problem/Topic

ii. 'DIRECT' the Problem/Topic via $\mathrm{D}, \mathrm{I}^{2}, \mathrm{R}^{3}, \mathrm{E}, \mathrm{C}^{2}, \mathrm{~T}^{2}$

iii. 'DEVECQUIT' the Problem/Topic via D,E,V,E, $\mathrm{C}^{3}, \mathrm{Q}^{2}, \mathrm{U}, \mathrm{I}, \mathrm{T}^{2}$

iv. 'SCRIPT' out the Problem/Topic via $S^{3}, \mathrm{C}^{3}, \mathrm{R}, \mathrm{I}, \mathrm{P}, \mathrm{T}^{3}$

v. 'APPRAISE' the topic via A,P,P,R,A,I,S,E2 
Some of the basic assumption of KPS according to Kolawole and Olofin (2017) which has relevance to this study are:

1. Most of the teachers do not have good knowledge of the subject matter, nor well equipped with appropriate teaching method couple with good evaluating skills

2. Most of the teachers are not usually familiar with how to make teaching, learning, solving and evaluation procedures go simultaneously.

3. Most of the teachers do not first of all identify relevant Keywords(K), Terms(T) and (IKTT) Terminologies (T), PASSWORD (Behavioural Objective) and Domain before embarking on teaching -Learning - Solving - Evaluation process. First step in (KPS).

4. Most of the teachers teach emblock without (i) classifying the topics into teachable subtopics i.e. DIRECT ${ }^{3}$ (ii) Defining, Identifying, Recognizing, Enumerating and Classifying the topics into teachable subtopics. Step 2 in KPS (DIRECT)

5. Most teachers are not used to Discuss, Explain, Verify, Interpreting, translating and interpreting relevant keywords, Terms and Terminologies before solving, computing and calculating processes. Step 3 in KPS (DEVECQUIT)

6. Most teachers usually start their lessons with examples calculations without any reference to the meaning of all relevant keywords, Terms and Terminologies of the subject matter. Step 4 in KPS (SCRIPTS)

7. Most teachers are not used to applying summarizing, revising inducing and deducing, assessing, appraising and examining/evaluating of the topic both life situations. Step 5 in KPS (APPRAISE.)

8. Most of the teachers construct test without following all necessary steps in text construction and without any reference to test blue print.

9. Most of the teachers do not summarize, draw conclusion and assess the students. Likewise teachers do not apply problem to everyday life.

10. Most of the teachers do not have question bank which ought to have been generated from their lesson note, classwork, assignment, achievement tests conducted in the class, and previous past questions.

Kolawole and Ojo (2016) conducted a study entitled "Statistical Analysis of the Effects of Kolawole's Problem-Solving (KPS) and Conventional Teaching Methods on the Academic Performance and Retention of Senior Secondary School Students in Mathematics in Ekiti State, Nigeria" with a sample of 400 students. The result of study showed that all the sampled students were homogeneous at the commencement of the study. There were main, joint and individual significant teaching effects of the Kolawole's Problem-Solving (KPS) and conventional methods on academic performance, and retention of senior secondary school students in Mathematics. Based on the findings it could be concluded that Kolawole's ProblemSolving (KPS) strategy is more effective method and students retained more knowledge than conventional method. Kolawole's Problem-Solving (KPS) strategy of instruction is neither location nor gender biased.

Ojo (2018) conducted a study entitled "Effects of Two Problem Solving Methods on Senior Secondary School Students Learning Outcomes in Simultaneous Equations in Ekiti State, Nigeria" with a sample of 302 students. The result of study showed that KPS is most effective for enhancing better students' performance in simultaneous equations, followed by Polya method and lastly conventional method. As effective as Kolawole's Problem-Solving (KPS) strategy was, the strategy was not gender and location biased.

Kolawole's problem-solving teaching strategy appears to be critical to students' school achievement in Mathematics, which seems to be cost effective compared to other strategies of 
teaching. Therefore, the present study investigates the effect of Kolawole's Problem-Solving strategy on the academic performance of secondary school students in Mathematics in Nigeria.

\section{Purpose of the Study}

The purpose of the study was to examine the effects of KPS teaching strategy on the academic performance of secondary school students in Mathematics in Nigeria. Specifically, the study examined:

i. which of the strategies (KPS or conventional) would be the more effective in the teaching of Mathematics;

ii. the performance of students in Mathematics exposed to KPS and conventional strategies in South West, South East and North Central;

iii. the difference in the pre-test mean score of students exposed to KPS and conventional strategies;

iv. the difference in the post-test mean score of students exposed to KPS and conventional strategies;

v. the difference in the academic performance of students exposed to KPS based on their geo-political zone;

\section{Research Questions}

The following research questions were raised to guide the study:

1. Which of the strategies (KPS or conventional) would be the more effective in the teaching of Mathematics?

2. What are the performance of students in Mathematics exposed to KPS and conventional strategies in South West, South East and North Central?

\section{Research Hypotheses}

The following null hypotheses were postulated for this study.

1) There is no significant difference in the pre-test mean score of students exposed to KPS and conventional strategies.

2) There is no significant difference in the post-test mean score of students exposed to KPS and conventional strategies.

3) There is no significant difference in the academic performance of students exposed to KPS strategy based on their geo-political zone.

\section{METHODOLOGY}

Quasi - experimental pre-test and post-test two group design (one experimental group and one control group) was used in the study. The pattern of the experimental design is as shown below.

$\mathrm{E}_{1}: \mathrm{O}_{1} \mathrm{X}_{1}$

$\mathrm{O}_{2}$ : Experimental group

$\mathrm{C}: \mathrm{O}_{3} \mathrm{X}_{\mathrm{c}}$

$\mathrm{O}_{4}$ : Control group

Where

$\mathrm{O}_{1}, \mathrm{O}_{3}$ - Observations before treatment

$\mathrm{O}_{2}, \mathrm{O}_{4}-$ Observations after treatment

$\mathrm{X}_{1}$ - Treatment via KPS strategy

$X_{c}$ - Treatment via Conventional Strategy 
The targeted population for the study consisted of all the Senior Secondary School (S.S.S.) two students in public secondary schools in three geo-political zones of Nigeria namely South-East, North Central and South-West. The sample consisted of 562 S.S.S. 2 students (class intact size) drawn from eighteen public secondary schools in three geo-political zones of Nigeria namely South-East, North-Central and South-West. The sample was selected using multistage sampling procedure.

Performance Test in Mathematics (PTM) was used to collect relevant data for this study. PTM measured students' academic performance in Mathematics. It consisted of section A and B, section A sought for the bio-data of the respondents. Section B of PTM consisted of 50 objectives items with five options made of thirteen questions on Knowledge, thirteen questions on Comprehension, seven questions on Application, seven questions on Analysis, five questions on Synthesis and five questions on Evaluation.

The face and content validity of Performance Test in Mathematics (PTM) was ensured by experts in Tests and Measurement and Mathematics Education. The reliability of PTM was carried out by administering it on 40 respondents in one of the schools outside the sampled area using test re-test method. These respondents had been taught the subject matter and were of comparable age with the respondents who participated in this study. Within a period of two weeks, the instrument was re-administered on the same respondents. The data extracted was collated and analyzed using the Pearson's Product Correlation Method, which yielded reliability co-efficient of 0.76 .

The study was carried out in three phases namely pre-treatment stage, treatment stage and post-treatment stage. The research questions were answered using descriptive statistics while the three hypotheses were analyzed by t-test, Analysis of Variance (ANOVA) and Post-hoc Analysis (Scheffe) at $\alpha=0.05$ level of significance.

\section{RESULTS}

Research Question 1: Which of the strategies (KPS or conventional) would be the more effective in the teaching of Mathematics?

Table 1: Mean and standard deviation of pre-test and post-test scores of students exposed to KPS and conventional strategies

\begin{tabular}{|c|c|c|c|c|c|}
\hline Strategies & Test & $\mathbf{N}$ & Mean & S.D & Mean Diff. \\
\hline \multirow{2}{*}{ KPS } & Pre Test & \multirow{2}{*}{270} & 11.80 & 0.86 & \multirow{2}{*}{23.71} \\
\hline & Post Test & & 35.51 & 4.00 & \\
\hline \multirow{2}{*}{ Conventional } & Pre Test & \multirow{2}{*}{292} & 11.91 & 0.91 & \multirow{2}{*}{10.72} \\
\hline & Post Test & & 22.63 & 4.21 & \\
\hline Total & & 562 & & & \\
\hline
\end{tabular}

From Table 1, it is shown that the mean difference in students' performance in Mathematics between pre-test and post-test scores for KPS strategy is 23.71 and conventional method is 10.72. It appears that the use of KPS and conventional strategies influences students' performance in Mathematics with KPS strategy being the more effective method in the teaching of Mathematics. The graphical representation below further shows the more effective method in the teaching of Mathematics. 
Figure i: Pre-test and Post-test mean scores of students exposed to KPS and conventional strategies

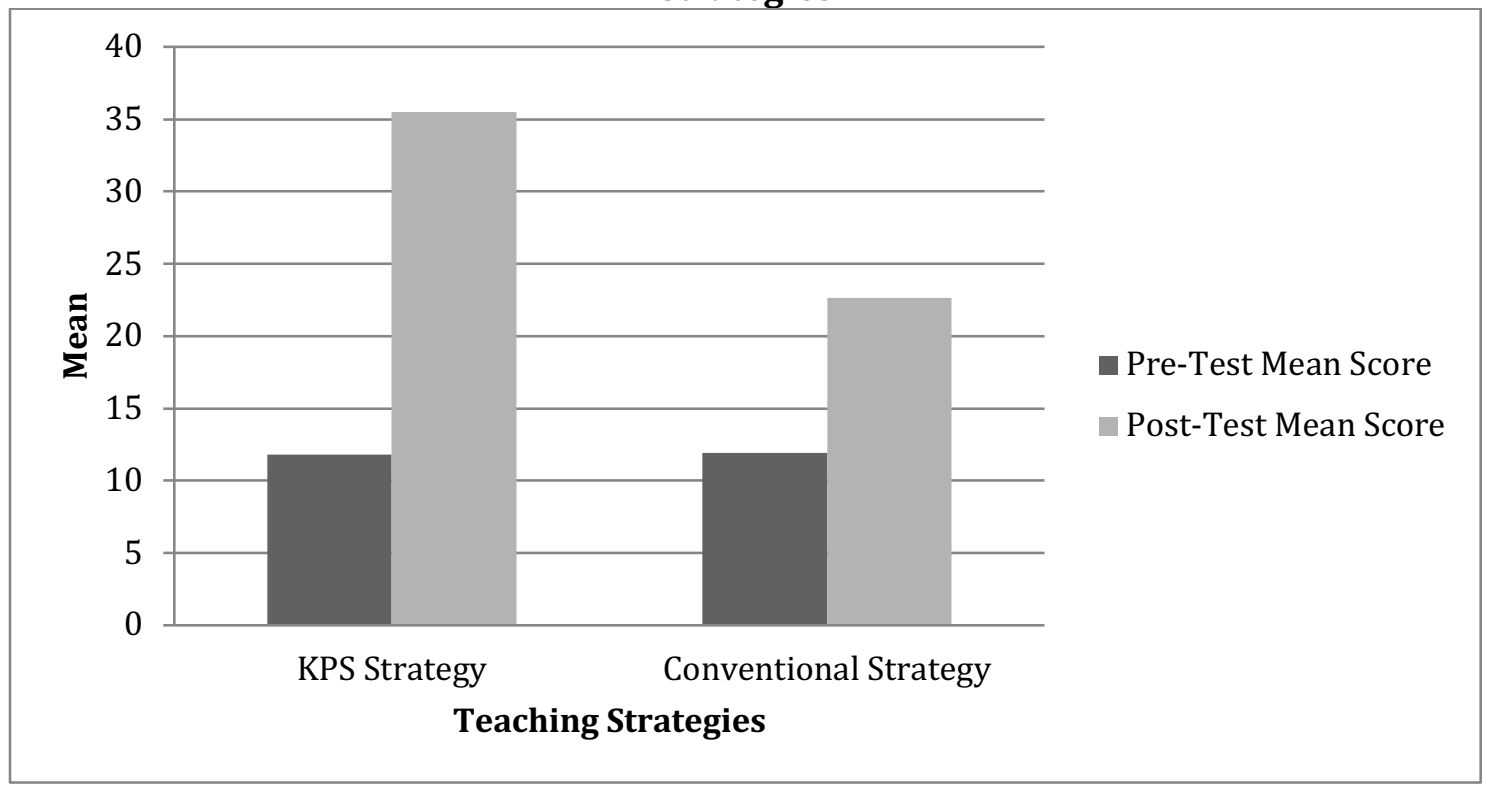

Research Question 2: What are the performance of students in Mathematics exposed to KPS and conventional strategies in South West, South East and North Central geo-political zones?

Table 2: Mean and standard deviation of post-test scores of students exposed to KPS and conventional strategies

\begin{tabular}{|l|c|c|c|c|}
\hline Geo-political Zone & Test & N & Mean & S.D \\
\hline \multirow{2}{*}{ South West } & KPS & 97 & 36.52 & 2.87 \\
\cline { 2 - 5 } & Conventional & 101 & 22.54 & 4.03 \\
\hline \multirow{2}{*}{ South East } & KPS & 77 & 38.26 & 3.80 \\
\cline { 2 - 5 } & Conventional & 96 & 22.46 & 4.21 \\
\hline \multirow{2}{*}{ North Central } & KPS & 96 & 32.28 & 2.78 \\
\cline { 2 - 5 } & Conventional & 95 & 22.63 & 4.42 \\
\hline Total & \multicolumn{3}{|l}{} \\
\hline
\end{tabular}

Table 2 shows the mean post-test scores of students exposed to KPS and conventional strategies in South West, South East and North Central geo-political zones respectively. The mean post-test score of students in South West geo-political zone exposed to KPS strategy is 36.52 while that of those exposed to conventional strategy is 22.54 . The mean post-test scores of students in South East geo-political zone exposed to KPS strategy and conventional strategy are 38.26 and 22.46 respectively. Lastly, the mean post-test score of students in North Central geo-political zone exposed to KPS strategy and conventional strategy are 32.28 and 22.63 respectively. The graphical representation below further shows the students' performance exposed to KPS and conventional strategies in the three geo-political zones. 
Figure ii: Performance of students in Mathematics exposed to KPS and conventional strategies in three geo-political zones

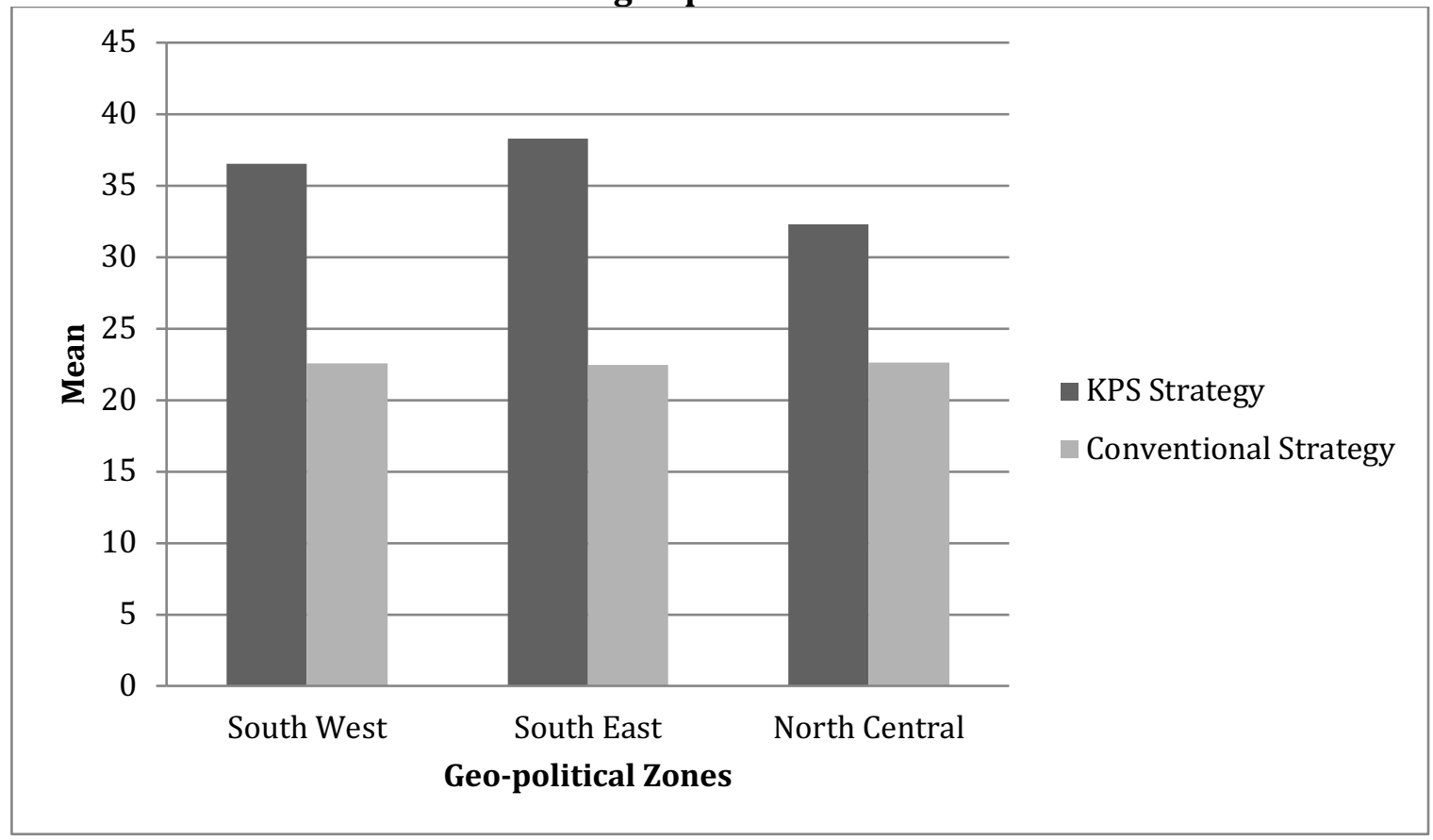

\section{Testing of Hypotheses}

Hypothesis 1: There is no significant difference in the pre-test mean score of students exposed to KPS and conventional strategies.

Table 3: t-test analysis for Pre - test Mean Scores of Students in Experimental and Control

\begin{tabular}{|l|c|c|c|c|c|c|}
\hline Variations & $\mathbf{N}$ & Mean & SD & df & $\mathbf{t}_{\text {cal }}$ & P \\
\cline { 1 - 4 } KPS & 270 & 11.80 & 0.86 & \multirow{2}{*}{560} & \multirow{2}{*}{1.480} & \multirow{2}{*}{0.139} \\
\cline { 1 - 4 } Conventional & 292 & 11.91 & 0.91 & & & \\
\hline
\end{tabular}

$\mathrm{P}>0.05$

Table 3 shows that the $t$-cal value of 1.480 is not significant because the $P$ value $(0.139)>0.05$. This implies that null hypothesis is not rejected. Hence, there is no significant difference in the pre-test mean score of students exposed to KPS and conventional strategies. The students in both groups are homogeneous at the commencement of the study.

Hypothesis 2: There is no significant difference in the post-test mean score of students exposed to KPS and conventional strategies.

Table 4: t-test analysis for Post - test Mean Scores of Students in Experimental and Control Groups

\begin{tabular}{|l|c|c|c|c|c|c|}
\hline Variations & $\mathbf{N}$ & Mean & SD & df & $\mathbf{t}_{\text {cal }}$ & P \\
\hline KPS & 270 & 35.51 & 4.00 & \multirow{2}{*}{560} & \multirow{2}{*}{37.115} & \multirow{2}{*}{$0.000^{*}$} \\
\cline { 1 - 4 } Conventional & 292 & 22.63 & 4.21 & & & \\
\hline
\end{tabular}

$* \mathrm{P}<0.05$

Table 4 shows that the $t$-cal value of 37.115 is significant because the $P$ value $(0.000)<0.05$. This implies that null hypothesis is rejected. Hence, there is significant difference in the post- 
test mean score of students exposed to KPS and conventional strategies. The mean score showed a significant difference of 12.88 in favour of students exposed to KPS strategy.

Hypothesis 3: There is no significant difference in the academic performance of students exposed to KPS strategy based on their geo-political zone

Table 5: Analysis of Variance (ANOVA) for difference in academic performance of students exposed to KPS strategy based on their geo-political zone

\begin{tabular}{|l|c|c|c|c|c|}
\hline Groups & Sum of Squares & df & Mean Square & F & Sig. \\
\hline Between Groups & 1681.047 & 2 & 840.523 & & \\
\cline { 1 - 3 } Within Groups & 2624.438 & 267 & 9.829 & \multirow{2}{*}{$85.512^{*}$} & .000 \\
\cline { 1 - 4 } Total & $\mathbf{4 3 0 5 . 4 8 5}$ & $\mathbf{2 6 9}$ & & & \\
\hline
\end{tabular}

$* \mathrm{P}<0.05$

The result presented in table 5 showed that F-cal value of 85.512 is significant because the $P$ value $(0.000)<0.05$ at 0.05 . Hence, the null hypothesis is rejected. This implies that there is significant difference in the academic performance of students exposed to KPS strategy based on their geo-political zone. In order to investigate the source of the differences observed, Post hoc analysis (Scheffe) with mean difference was carried out.

Table 6: Scheffe Post - hoc test and mean for observed difference in students' performance in the groups

\begin{tabular}{|l|c|c|c|c|}
\hline Groups & & South West & South East & North Central \\
\cline { 3 - 5 } & Mean & 36.52 & 38.26 & 32.28 \\
\hline South West & 36.52 & & & \\
\hline South East & 38.26 & $1.7443^{*}$ & & \\
\hline North Central & 32.28 & $4.2342^{*}$ & $5.9785^{*}$ & \\
\hline
\end{tabular}

$* \mathrm{P}<0.05$

In table 6, a significant difference was found between the performance of students exposed to KPS strategy in South West and South East in favour of students in South East. Also there was significant difference between the performance of students exposed to KPS strategy in South West and North Central in favour of students in South West. There was difference between the performance of students exposed to KPS strategy in South East and North Central in favour of students in South East.

The result of post - hoc test also showed that, of all students exposed to KPS strategy in the three geo-political zones South East performed best. They performed significantly better than their counterparts in the South West and North Central geo-political zones respectively. Again, those exposed to KPS strategy in South West performed better than those in North Central, which indicates that students exposed to KPS strategy in North Central performed worst.

\section{DISCUSSION}

The finding of this study revealed that, the performance of students in both experimental and control groups in pre-test were low and do not differ statistically. This finding established the homogeneity of the two groups involved in the study prior to the experiment. In other words, it could be said that the knowledge baseline for the two groups involved in the study are equal. Consequently, any significant difference recorded afterwards would not be ascribed to chance, but to the specific treatment applied. 
The findings of this study revealed that there was significant difference in the post-test mean score of students exposed to KPS and conventional strategies. There was a better improvement in the performance of students resulting from their exposure to KPS. This implies that the introduction of KPS to the experimental group made them to perform better than the control group that was not exposed to treatment. The findings of Kolawole and 0jo (2016), Kolawole, Oladosu and Ajetunmobi (2013) show that KPS strategy application in some schools yielded better results than the conventional method. Seweje (2010) concluded that good teaching strategies have the potent to improve cognition of students. This also justifies the earlier postulate of this study that KPS could facilitate meaningful learning of Mathematics.

The result further revealed that, there is significant difference in the academic performance of students exposed to KPS strategy based on their geo-political zone. The result of post - hoc test also showed that students exposed to KPS strategy in South East performed best. They performed significantly better than their counterparts in other South West and North Central. Moreso, those exposed to KPS strategy in South West performed better than those in North Central, which indicates that students exposed to KPS strategy in North Central performed worst. Utibe (2015) concluded that the zones in the country are not performing equally in mathematics; there are zones with significantly better performance and those with consistently poor performances.

\section{CONCLUSION}

Based on the findings of this study, it could be concluded that, the two groups (KPS and Conventional) were homogeneous at the commencement of the experiment. The use of KPS enhanced better performance of students in Mathematics than the conventional strategy. Also, there was difference in students' performance in Mathematics when exposed to KPS based on their geo-political areas as students from South East geo-political performed significantly better than their counterparts in the South West and North Central.

\section{RECOMMENDATIONS}

Based on the findings of this study, the following recommendations were made.

1) The use of Kolawole's Problem-Solving (KPS) strategy should be encouraged in Mathematics class in secondary schools so as to enhance better academic performance of students in Mathematics.

2) Authors of Mathematics textbooks should adopt Kolawole's Problem-Solving (KPS) strategy five steps in developing all chapters of their book.

\section{References}

Joseph, E. U. (2012). Psycho-Academic variables and mathematics achievement of 9th grade students. Nigeria British Journal of Education, Society \& Behavioural Science, 2(2), 174-83.

Kolawole, E. B. (2013). Kolawole's Problem Solving Method (KPS): A Panacea to Mathematical and Life's Problems. Standard Journal of Education and Essay, 1(8), 131 - 141. http://www.standresjournal.org/journals

Kolawole, E. B. \& Ojo, O. (2016). Statistical Analysis of the Effects of Kolawole's Problem Solving (KPS) and Conventional Teaching Methods on the Academic Performance and Retention of Secondary School Students in Mathematics in Ekiti State, Nigeria. Research Journal of Education, 2(6), 100-109.

Kolawole, E. B., Oladosu, C. T. \& Ajetunmobi, O. (2013). Comparability of Effectiveness of Problem Solving Methods on Learners Performance in Mathematics. Unique Journal of Educational Research, 1(2), 012 - 019.

Kolawole, E. B. \& Olofin, S. O. (2017). Content Analysis of Kolawole's Problem Solving (KPS) Method. Book of Reading of Prof. M.F. Alonge, Journal of Tests and Measurement, 47 - 84

Kolawole, E. B. \& Olofin, S. O. (2018). Effects of Goal Setting Skill and Peer Modelling Strategies on Academic Performance of Ekiti State Students in Mathematics. In Book of Reading of Prof. Onwuamanam, Ado - Ekiti: University Press, 293 - 303 
Kolawole, E. B. \& Popoola A. A. (2009). Effect of using problem solving method in the teaching of senior secondary school mathematics on students' academic performance. International journal of Mathematics Education, 16 (2), $212-231$

Ojo, O. F. (2018). Effects of Two Problem Solving Methods on Senior Secondary School Students Learning Outcomes in Simultaneous Equations in Ekiti State, Nigeria, Unpublished Ph.D Thesis, Department of Science Education, Ekiti State University

Seweje, R. O. (2010). Science education and science teaching methods. Ado-Ekiti: Greenline Publishers

Utibe, U. J. (2015). A Decade of Candidates' Performances in NECO-SSCE Mathematics in Nigeria. Journal of Education and Practice, 6(2), 25 -30 